\title{
Evaluation of options portfolios for exchange rate hedges
}

\author{
Miguel Jiménez-Gómez ${ }^{1}$, Natalia Acevedo-Prins ${ }^{2}$, Miguel Rojas-López ${ }^{3}$ \\ ${ }^{1,3}$ Facultad de Minas, Universidad Nacional de Colombia, Medellín, Colombia \\ ${ }^{1,2}$ Facultad de Ciencias Económicas y Administrativas, Instituto Tecnológico Metropolitano-ITM, Colombia
}

\begin{tabular}{|c|c|}
\hline Article Info & ABSTRACT \\
\hline Article history: & In this paper evaluate six exchange rate hedging strategies with financial \\
\hline Received Mar 26, 2020 & $\begin{array}{l}\text { options from the OTC market in Colombia. Three hedging strategies for } \\
\text { importers and three for exporters were raised. The coverage for importers }\end{array}$ \\
\hline Revised Jun 27, 2020 & was carried out with the traditional strategy of long call, bull call spread and \\
\hline Accepted Jul 13, 2020 & $\begin{array}{l}\text { bull put spread, the last two correspond to options portfolios. The coverage } \\
\text { for importers was carried out with the traditional strategy of long put, bear }\end{array}$ \\
\hline Keywords: & $\begin{array}{l}\text { call spread and bear put spread, the last two correspond to options portfolios } \\
\text { to determine the best hedging strategy, the currency price was modeled with }\end{array}$ \\
\hline $\begin{array}{l}\text { Exchange rate hedges } \\
\text { Options portfolios } \\
\text { Value at risk }\end{array}$ & $\begin{array}{l}\text { a Wiener process and the VaR for the six covered scenarios was calculated } \\
\text { and compared with the VaR of the uncovered scenario. The results shown by } \\
\text { the six hedging strategies manage to mitigate the exchange risk, but the most } \\
\text { efficient strategies are the traditional ones for both importers and exporters. }\end{array}$ \\
\hline
\end{tabular}

This is an open access article under the CC BY-SA license.

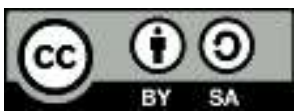

Corresponding Author:

Miguel Jiménez-Gómez

Instituto Tecnológico Metropolitano-ITM

Universidad Nacional de Colombia

Calle 54 A \#30-01, Medellín, Colombia

Email: luisjimenez@itm.edu.co

\section{INTRODUCTION}

Since the collapse of the Bretton Woods exchange system in March 1973, the international currency market has developed towards currency liberalization. Since then, researchers have studied sources of currency risk to understand why exchange rates fluctuate, because currency market fluctuations are more frequent and exchange rate risk prevails. With the globalization of the economy, multinational companies face this market risk. Therefore, how to manage foreign exchange risk has become important for companies and researchers $[1,2]$.

Multinational companies with expected future cash flows in currencies are directly exposed to exchange rate movements. This is known as exchange rate risk or currency risk. However, the other companies are exposed indirectly (competitive environment). This exchange exposure also affects the value of the company. In importing and exporting companies, with direct exposure to foreign exchange risk, the exposure covers transactions such as accounts receivable or accounts payable in foreign currency. Companies with indirect exposure, market risk arises from the competitive environment in which the company operates. Companies that manufacture and sell only locally will be exposed to a strengthening of the local currency as imports from competing companies become cheaper [3].

From the approach of the valuation of companies and the classical financial theory of Modigliani and Miller, the financial hedges are not important and are not necessary to realize since the markets are perfect and do not have frictions. However, from a modern approach where markets are imperfect, financial hedges increase the value of companies. The above is due to the existence of financial difficulties [4-7]. Financial hedges avoid financial difficulties by obtaining a lower probability of default by reducing exposure 
to foreign exchange risk, this causes companies to obtain more financing, better interest rates and higher tax shields $[8,9]$. From the above, the value of the company increases.

To mitigate foreign exchange risk, two means are used. One is financial coverage using financial derivatives such as futures and financial options. The second is the operational coverage through the operation of the organization [10]. When managing long-term currency risk, Ito et al. [11] they affirm that companies must develop operational coverage strategies and financial coverage strategies. The main reasons for the hedges are the minimization of the impact of currency movements on the cash flows of the companies and the reduction of the probability of financial problems. There are different methods to quantify currency risk. The classic measure is variance, measuring the variance of cash flows, but currently this has focused on using the value at risk $(\mathrm{VaR})$ and the conditional value at risk $(\mathrm{CVaR})$. VaR is the possible loss with a probability and a time horizon. CVaR is the conditional expectation of losses above VaR [12-14].

Financial derivatives such as futures and options can be used to hedge exchange rate risk. There is scientific literature focused on exposure to exchange rate risk in the futures market. However, futures contracts are standardized in the stock exchanges and this standardization increases the liquidity risk in the futures market. On the other hand, hedging strategies with financial options are more flexible and varied and do not require initial margin or margin of daily variation as in the future. In addition, since financial options are non-linear financial instruments, they could be used to cover non-linear risk [15]. The financial currency option gives the holder the right to buy or sell an amount of foreign currency at a specific price called strike at expiration. For hedging purposes, a company can buy purchase options against the appreciation of the foreign currency and buy a sale option against the depreciation of the foreign currency. In this way, financial options are widely used to manage foreign exchange risk [16, 17]. Some studies that analyze exchange rate hedges with financial options, may refer to [2, 18-24].

The objective of this paper is to quantify the exchange risk for importers and exporters in Colombia, evaluate some hedging strategies with financial options and determine the best strategy that minimizes the impact of currency variations on companies. The risk is quantified by means of the VaR by the Monte Carlo simulation method. This paper contributes to the absence of studies in the literature that analyze exchange hedging strategies with a portfolio of options in the Colombian market. Additionally, the way to quantify the exchange risk with the VaR is novel because most studies do so based on the variance.

\section{RESEARCH METHOD}

Depending on the exposure to foreign exchange risk, the way of performing coverage depends. There are currency buyers who have a risk exposure when the spot price of the currency increases. Likewise, there is exchange risk with the sellers of the currency when the spot price decreases. This is the market risk that importers and exporters have, respectively. The OTC (over the counter) market in Colombia offers financial products to mitigate this risk, which can be done using call or put options. Importers use long call options and exporters long put options for hedging purposes. In long call options the compensation is $\mathrm{S}_{\mathrm{T}}-\mathrm{K}$ when the difference is positive, otherwise, the compensation is zero. In long put options the compensation is $\mathrm{K}-\mathrm{S}_{\mathrm{T}}$ when the difference is positive, or zero when the difference is negative. The coverage strategies with these options are the traditional strategies. The result of coverage with these options is shown in (1) and (2), where $S_{T}$ corresponds to the price paid for the currency on the expiration date of the currency, and $\mathrm{K}_{1}$ or $\mathrm{K}_{2}$ the strike prices of each of the options. As with these strategies the options are purchased, Call1 represents the value of the Call $1_{1}$ option premium with $\mathrm{K}_{1}$ and Put $\mathrm{P}_{1}$ the premium of the Put option with $\mathrm{K}_{1}$.

$$
\begin{aligned}
& \text { Buyer hedge price }_{\text {Long Call }}=\left|-S_{T}+\operatorname{Max}\left[S_{T}-K_{1} ; 0\right]-\operatorname{Call}_{1}\right| \\
& \text { Seller hedge price } \text { Long Put }_{T}=S_{T}+\operatorname{Max}\left[K_{1}-S_{T} ; 0\right]-\text { Put }_{1}
\end{aligned}
$$

There are other options coverage strategies offered in the OTC market in Colombia that make up financial options portfolios. These portfolios are the combination of two or more options and have an associated name. The portfolio of options called bull call spread is useful for importers, in this hedging strategy, call options with a low strike $\left(\mathrm{K}_{1}\right)$ are purchased and call options with higher strike $\left(\mathrm{K}_{2}\right)$ are sold. For the exporters the bear call spread portfolio is offered, this strategy consists of selling Call options with low strike price $\left(\mathrm{K}_{1}\right)$ and buying call options with higher strike $\left(\mathrm{K}_{2}\right)$. The results of the hedges with these two strategies for importers are shown in (3) and (4).

$$
\begin{aligned}
& \text { Buyer hedge price } \text { Bull Call spread }_{1}=\mid-S_{T}+\text { Bull Call Spread } \mid \\
& \text { Seller hedge price } \text { Bear Call spread }=S_{T}+\text { Bear Call Spread }
\end{aligned}
$$


The two previous hedging strategies can also be done with only Puts options, these strategies are called bull put spread for importers and bear put spread for exporters. In (5) and (6) they show the result of the coverage with these two options portfolios.

$$
\begin{aligned}
& \text { Buyer hedge price }_{\text {Bull Put spread }}=\mid-S_{T}+\text { Bull Put Spread } \mid \\
& \text { Seller hedge price } \text { Bear Put Spread }=S_{T}+\text { Bear Put Spread }
\end{aligned}
$$

The risk profiles of the six coverage strategies mentioned above are shown in Figure 1.
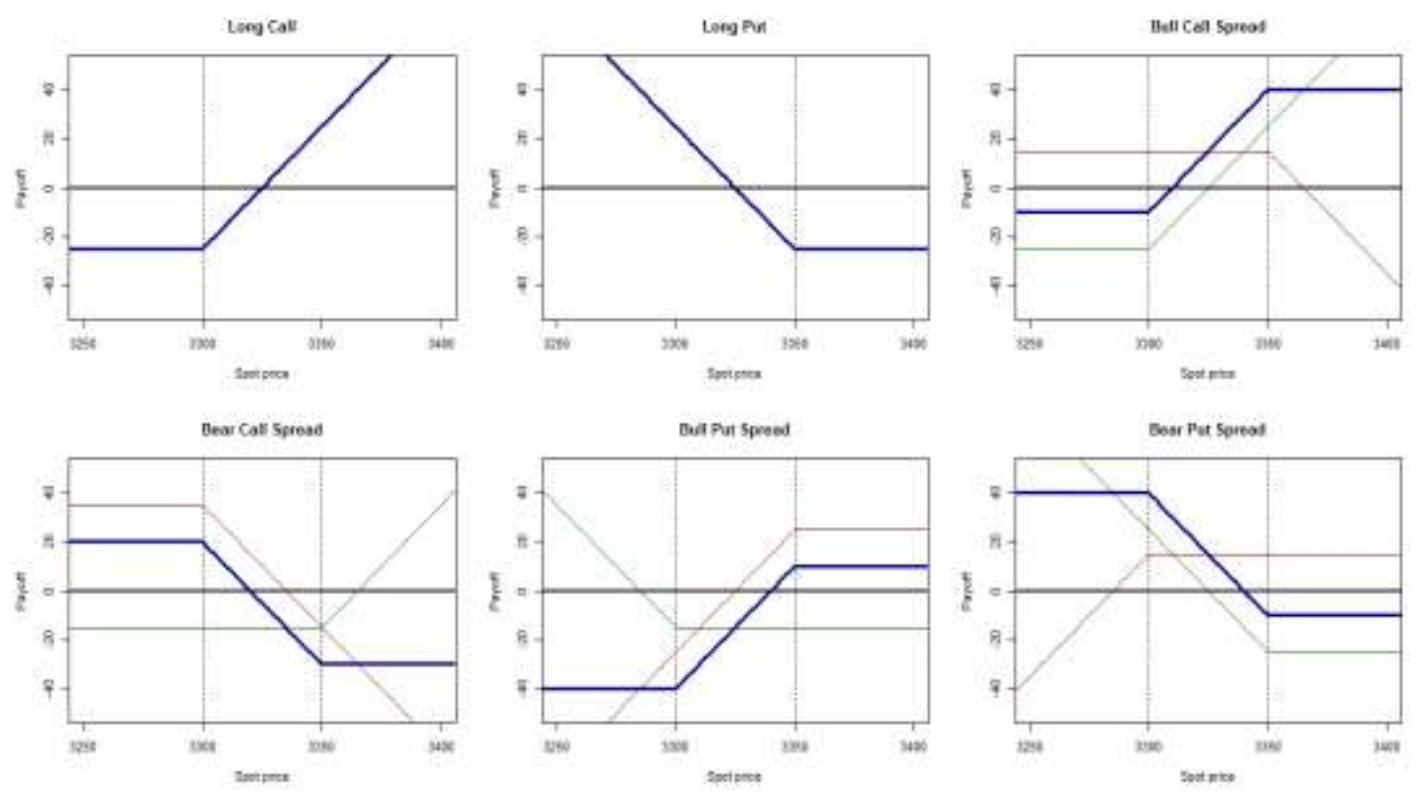

Figure 1. Coverage strategies

In this paper the six coverage strategies mentioned above were applied, the comparison is made with the scenario without coverage corresponding to the value of $S_{T}$. In this way, there are seven scenarios. $S_{T}$ was modeled with the geometric brownian movement shown in (7) [25].

$$
S_{T}=S_{0} e^{\left[\left(\mu-\frac{\sigma^{2}}{2}\right) \Delta T+\sigma \sqrt{\Delta T} \epsilon\right]}
$$

In (6) $S_{0}$ is the market price of the currency at the time of modeling, $\mu$ is the expected value of the continuous returns of a currency history, $\sigma$ is the standard deviation, $\Delta \mathrm{T}$ the period of time to model and $\epsilon$ is the continuous random variable that it distributes as a normal Standard [26, 27]. Financial options were valued by the black-scholes and merton method with the variation for currencies shown in (8), (9) and (10) [28].

$$
\begin{aligned}
& \text { call }=S_{0} e^{-r_{f} t} N\left(d_{+}\right)-K e^{-r t} N\left(d_{-}\right) \\
& \text {put }=K e^{-r t} N\left(-d_{-}\right)-S_{0} e^{-r_{f} t} N\left(-d_{+}\right) \\
& d_{ \pm}=\frac{\log \left(\frac{S_{0}}{K}\right)+\left(r-r_{f} \pm \frac{1}{2} \sigma^{2}\right) t}{\sigma \sqrt{t}}
\end{aligned}
$$

After modeling the spot price and calculating the options premiums, a Monte Carlo simulation with 50,000 iterations was carried out to determine the possible results of the six scenarios with coverage and the scenario without coverage. The modeling and simulation were carried out for one month, calculating in each scenario the prices without coverage corresponding to the expected spot price and the six prices with 
coverage. To determine the benefits of coverage, the percentiles of $5 \%$ and $95 \%$ and the standard deviation were calculated for both the uncovered price and the six covered prices. For importers the VaR is measured with the $95 \%$ percentile and for exporters with the $5 \%$ percentile, this way of measuring the risk corresponds to the VaR method by Monte Carlo simulation. It is expected that with coverage the VaR will decrease and in turn the standard deviation. If the above occurs, it would be shown that the risk is reduced with coverage, in this case the foreign exchange risk, because the volatility of the projected scenarios would be lower and there would be less losses.

On the other hand, daily historical data of the five-year exchange rate was used from February 2015 to February 2020, obtaining 1,225 data. Because the models used are continuous logarithmic yields were calculated. With these yields the average represents the drift $(\mu)$ and the standard deviation represents $\sigma$ for the geometric brownian movement. For the risk-free rates of Colombia (r), the interbank rate (IBR) in effect for one month was used, the same was done for the United States free rate $\left(\mathrm{r}_{\mathrm{f}}\right)$, the American Treasury rate in effect for one month was used. Then, the rates were converted to continuous time and divided by 12 to have them in the same units as $\mu$ and $\sigma$.

\section{RESULTS AND ANALYSIS}

Three exchange hedging strategies for importers and three strategies for exporters in Colombia were used. Six scenarios with coverage and one scenario without coverage were obtained. With the seven scenarios, empirical distributions were obtained using the Monte Carlo simulation. The uncovered scenario obtained a standard deviation of $\$ 123,5 \%$ percentile of $\$ 3,209$ and $95 \%$ percentile of $\$ 3,614$. The objective of each proposed coverage strategy is to obtain a smaller standard deviation and depending on whether it is for exporter or importer, increase the value of the $5 \%$ percentile and decrease the value of the 95\% percentile, respectively. For the exporter, the mitigated risk is evidenced if a higher value is obtained from the worst scenarios for a currency seller, that is, the VaR decreases. For the importer, the risk is mitigated if the worst-case scenario, measured by the $\operatorname{VaR}(95 \%$ percentile), is lower to obtain a purchase of the currency at a better price, that is, the $95 \%$ percentile is lower. The above is evidenced in Table 1 with the results of the six scenarios with coverage.

Table 1. Results six scenarios with coverage

\begin{tabular}{cccc}
\hline \multicolumn{4}{c}{ Buyer Coverage } \\
\hline & Call & Bull Call Spread & Bull Put Spread \\
Standard deviation & $\$ 34$ & $\$ 108$ & $\$ 108$ \\
$5 \%$ percentile & $\$ 3,329$ & $\$ 3,246$ & $\$ 3,247$ \\
$95 \%$ percentile $(V a R)$ & $\$ 3,419$ & $\$ 3,601$ & $\$ 3,601$ \\
& Seller Coverage & \\
& Put & Bear Call Spread & Bear Put Spread \\
Standard deviation & $\$ 92$ & $\$ 108$ & $\$ 108$ \\
$5 \%$ percentile $($ VaR) & $\$ 3,324$ & $\$ 3,246$ & $\$ 3,247$ \\
$95 \%$ percentile & $\$ 3,588$ & $\$ 3,601$ & $\$ 3,601$ \\
\hline
\end{tabular}

Each of the scenarios with coverage manages to mitigate the exchange risk. However, the best hedging strategy is the traditional one, both for the importer and the exporter because the empirical distributions of these scenarios have the lowest standard deviation and lower VaR. The strategies with options portfolio reach similar results for importer and exporter coverage. It is emphasized that the empirical distributions of the strategies with coverage with portfolio of options have the same breadth because they have the same standard deviation. The traditional strategies, Long Call and Long Put, are the most efficient in exchange coverage, although with some strategies with options portfolios lower premiums are paid and in some cases, money is received for the options premiums. Table 2 shows the value that is paid or received for each of the coverage strategies.

Table 2. Value of premiums for each coverage strategy

\begin{tabular}{cc}
\hline Strategy & Premiun \\
\hline Call & $-\$ 119.303$ \\
Put & $-\$ 25.233$ \\
Bull Call Spread & $-\$ 37.069$ \\
Bull Put Spread & $\$ 12.794$ \\
Bear Call Spread & $\$ 37.069$ \\
Bear Put Spread & $-\$ 12.794$ \\
\hline
\end{tabular}


A comparison of the empirical distributions is shown in Figure 2. In each graph, the frequency histogram of the strategy with coverage is shown and the empirical distribution of the scenario without coverage is superimposed (blue line). The long call and long put strategies have no symmetric distributions. This is due to the fact that the strikes prices of the compensations make the final result decrease if it is Call coverage or increases if it is Put coverage. On the other hand, the empirical distributions of the strategies with options portfolios reach similar results and it is highlighted that they are similar to the empirical distribution of the scenario without coverage.
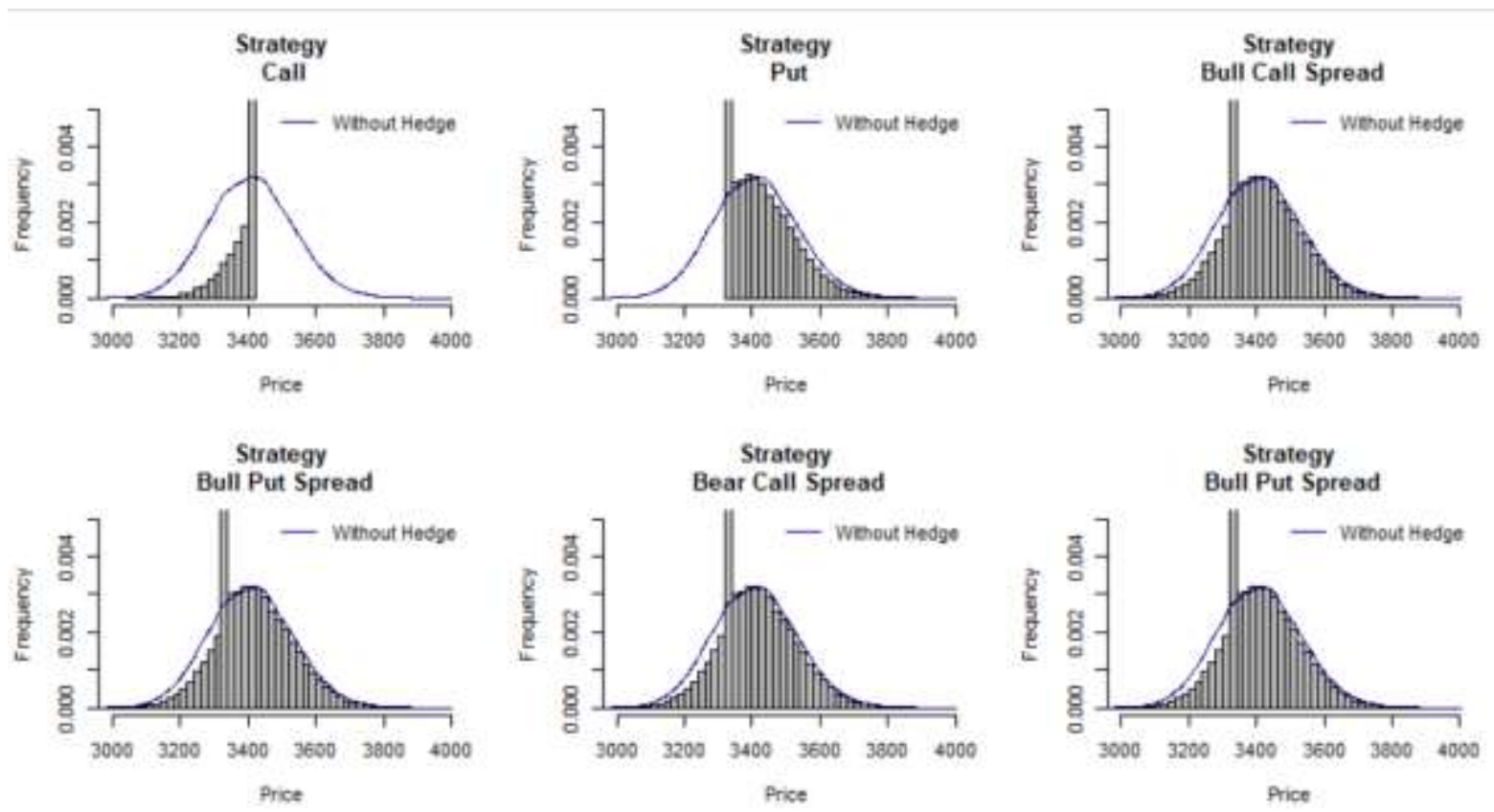

Figure 2. Histogram of frequency scenario without coverage and distribution scenarios with coverage

\section{CONCLUSION}

In this paper evaluate exchange rate hedging strategies for importers and exporters in Colombia using financial options portfolios. To measure the exchange risk, the $5 \% \mathrm{VaR}$ is applied with a daily time horizon. Three coverage strategies were proposed for both importers and exporters for a total of six scenarios with coverage. Traditional Long Call and Long Put strategies and options portfolios called Bull Call Spread, Bear Call Spread, Bull Put Spread and Bear Put Spread were evaluated. The six hedging strategies manage to mitigate the exchange rate risk for importers and exporters in Colombia. The above was determined by minimizing the risk measured by the VaR. The best coverage strategies are the traditional ones, although they are the most expensive strategies because they have the highest premium values, particularly Long Call. The other coverage strategies have similar results among them. It is proposed to carry out the research modeling the price of the currency with a process of jumps or process of reversion to the average with jumps and, in addition, to evaluate more hedging strategies with financial options that are offered in the OTC market in Colombia and evaluating them with the premium values found by the Black-Scholes and Merton method and with a variation of zero cost strategies for the options portfolios.

\section{REFERENCES}

[1] G. Li, J. Zhu, and J. Li, "Understanding bilateral exchange rate risks," J. Int. Money Financ., vol. 68, pp. 103-129, 2016.

[2] X. Yu, Z. Wan, X. Tu, and Y. Li, "The optimal multi-period hedging model of currency futures and options with exponential utility," J. Comput. Appl. Math., vol. 366, p. 112412, 2020.

[3] E. Hutson, E. Laing, and M. Ye, "Mutual fund ownership and foreign exchange risk in Chinese firms," J. Int. Financ. Mark. Institutions Money, vol. 60, pp. 169-192, 2019.

[4] M. M. Arnold, A. W. Rathgeber, and S. Stöckl, "Determinants of corporate hedging: A (statistical) meta-analysis," Q. Rev. Econ. Financ., vol. 54, no. 4, pp. 443-458, 2014. 
[5] Y. Ayturk, A. Osman, and S. Yanik, "Corporate derivatives use and firm value: Evidence from Turkey," Borsa Istanbul Rev., vol. 16, no. 2, pp. 108-120, 2016.

[6] J. Chen and T. D. King, "Corporate hedging and the cost of debt," J. Corp. Financ., vol. 29, pp. 221-245, 2014.

[7] C. W. Smith and R. M. Stulz, "The Determinants of Firms Hedging Policies," J. Financ. Quant. Anal., vol. 20, no. 4, pp. 391-405, 1985.

[8] D. Sprcic and Z. Sevic, "Determinants of corporate hedging decision: Evidence from Croatian and Slovenian companies," Res. Int. Bus. Financ., vol. 26, no. 1, pp. 1-25, 2012.

[9] D. M. Sprčić, M. Tekavcic, and Z. Sevic, "A review of the rationales for corporate risk management: fashion or the need?," Int. J. Econ. Sci. Appl. Res., vol. 1, no. 1, pp. 71-99, 2008.

[10] S. Vanitha and K. Saravanakumar, "The usage of gold and the investment analysis based on gold rate in India," Int. J. Electr. Comput. Eng., vol. 9, no. 5, pp. 4296-4301, 2019.

[11] T. Ito, S. Koibuchi, K. Sato, and J. Shimizu, "Exchange rate exposure and risk management: The case of Japanese exporting firms," J. Jpn. Int. Econ., vol. 41, pp. 17-29, 2016.

[12] S. Álvarez-díez, E. Alfaro-cid, and M. O. Fernández-blanco, "Hedging foreign exchange rate risk: Multi-currency diversification," Eur. J. Manag. BusinessEconomics, vol. 25, no. 1, pp. 2-7, 2016.

[13] P. Jorion, Value at risk: The new benchmark for managing financial risk, New York: McGraw Hill, 2002.

[14] O. Hadzic and S. Bisanovic, "Risk assessment for ancillary services," Int. J. Electr. Comput. Eng., vol. 9, no. 3, pp. 1561-1568, 2019.

[15] W. Guo, X. Yu, and Y. Jun, "Trade and currency options hedging model," J. Comput. Appl. Math., vol. 343, pp. 328-340, 2018.

[16] M. C. Chuang, C. H. Wen, and S. K. Lin, "Valuation and empirical analysis of currency options," Int. Rev. Econ. Financ., vol. 66, pp. 71-91, 2020.

[17] K. H. Kim, N. U. Kim, D. C. Ju, and J. H. Ri, "Efficient hedging currency options in fractional Brownian motion model with jumps," Phys. A Stat. Mech. its Appl., vol. 539, p. 122868, 2020.

[18] M. Barjaktarović, D. Karic, and R. Zecevic, "Currency options in function of currency risk hedging and speculating," Econ. Anal., vol. 44, no. 1-2, pp. 38-46, 2011.

[19] E. Bajo, M. Barbi, and S. Romagnoli, "Optimal corporate hedging using options with basis and production risk," North Am. J. Econ. Financ., vol. 30, pp. 56-71, 2014.

[20] D. Lien and Y. Tse, "Hedging downside risk: futures vs. options," Int. Rev. Econ. Financ., vol. 10, no. 2, pp. 159-169, 2001.

[21] A. Judge, "Why and how UK firms hedge," Eur. Financ. Manag., vol. 12, no. 3, pp. 407-441, 2006.

[22] C. S. Tai, "Asymmetric currency exposure and currency risk pricing," Int. Rev. Financ. Anal., vol. 17, no. 4, pp. 647-663, 2008.

[23] K. M. E. Dominguez and L. L. Tesar, "Exchange rate exposure,” J. Int. Econ., vol. 68, no. 1, pp. 188-218, 2006.

[24] J. F. Solomon and N. L. Joseph, "Which corporate hedging motives are appropriate? An institutional shareholders' perspective," Int. J. Financ. Econ., vol. 5, no. 4, pp. 339-347, 2000.

[25] H. Kleinert and J. Korbel, "Option pricing beyond Black-Scholes based on double-fractional diffusion," Physica A: Statistical Mechanics and its Applications, vol. 449, pp. 200-214, 2016.

[26] J. Hull, Options, futures, and other derivatives, 8th ed. Boston: Pearson Education, 2012.

[27] N. R. Sari, W. F. Mahmudy, A. P. Wibawa, and E. Sonalitha, "Enabling external factors for inflation rate forecasting using fuzzy neural system,” Int. J. Electr. Comput. Eng., vol. 7, no. 5, pp. 2746-2756, 2017.

[28] F. Black and M. Scholes, "The pricing of options and corporate liabilities," J. Polit. Econ., vol. 81, no. 3, pp. 637-654, 1973. 